\title{
OPEN Normobaric oxygen treatment for mild-to-moderate depression: a randomized, double-blind, proof-of-concept trial
}

\author{
Yehudit Bloch ${ }^{1,2,3}$, R. H. Belmaker ${ }^{4}$, Pesach Shvartzman ${ }^{5,6}$, Pnina Romem $^{1,10}$, \\ Arkady Bolotin 7 , Yuly Bersudsky ${ }^{8,9}$ \& Abed N. Azab ${ }^{1,2,9 凶}$
}

Oxygen enriched air may increase oxygen pressure in brain tissue and have biochemical effects even in subjects without lung disease. Consistently, several studies demonstrated that normobaric oxygen treatment has clinical benefits in some neurological conditions. This study examined the efficacy of normobaric oxygen treatment in subjects with depression. In a randomized, double-blind trial, 55 participants aged 18-65 years with mild to moderate depression (had a Hamilton Rating Scale for Depression [HRSD] score of $\geq 8$ ) were recruited to the study from the Southern district in Israel. Participants underwent a psychiatric inclusion assessment at baseline and then were randomly assigned to either normobaric oxygen treatment of $35 \%$ fraction of inspired oxygen or $21 \%$ fraction of inspired oxygen (room air) through a nasal tube, for 4 weeks, during the night. Evaluations were performed at baseline, 2 and 4 weeks after commencement of study interventions, using the following tools: HRSD; Clinical Global Impression (CGI) questionnaire; World Health Organization-5 questionnaire for the estimation of Quality of Life (WHO-5-OOL); Sense of Coherence (SOC) 13-item questionnaire; and, Sheehan Disability Scale (SDS). A multivariate regression analysis showed that the mean \pm standard deviation [SD] changes in the HRSD scores from baseline to week four were $-4.2 \pm 0.3$ points in the oxygen-treated group and $-0.7 \pm 0.6$ in the control group, for a between-group difference of 3.5 points $(95 \%$ confidence interval $[\mathrm{Cl}]-5.95$ to $-1.0 ; P=0.007)$. Similarly, at week four there was a between-group difference of 0.71 points in the $\mathrm{CGI}$ score $(95 \% \mathrm{CI}-1.00$ to $-0.29 ; \mathrm{P}=0.001)$. On the other hand, the analysis revealed that there were no significant differences in WHO-5-OOL, SOC-13 or SDS scores between the groups. This study showed a significant beneficial effect of oxygen treatment on some symptoms of depression.

Trial registration: NCT02149563 (29/05/2014).

Depression is a devastating mental illness causing immense suffering among affected subjects and their families and is associated with severe emotional, functional and financial burden ${ }^{1,2}$. Depression is a common disorder especially among women ${ }^{3,4}$, with a life-time prevalence ranging between 10 and $20 \%$ in the general population ${ }^{3,5}$. These estimations may be misleading, the actual numbers presumably even higher, recognizing the culturalassociated differences in inferring and diagnosing mental illness ${ }^{3,6}$. The most widely used treatment strategies

\footnotetext{
${ }^{1}$ Department of Nursing, Faculty of Health Sciences, School for Community Health Professions, Ben-Gurion University of the Negev, P.O.B 653, 8410501 Beer-Sheva, Israel. ${ }^{2}$ Department of Clinical Biochemistry and Pharmacology, Faculty of Health Sciences, Ben-Gurion University of the Negev, Beer-Sheva, Israel. ${ }^{3}$ Southern District Health Office, Ministry of Health, Beer-Sheva, Israel. ${ }^{4}$ Faculty of Health Sciences, Ben-Gurion University of the Negev, Beer-Sheva, Israel. ${ }^{5}$ Department of Family Medicine and Siaal Center for Community Research, The Haim Doron Division of Community Health, Faculty of Health Sciences, Kappy and Eric Flanders National Palliative Care Resource Center, Ben-Gurion University of the Negev, Beer-Sheva, Israel. ${ }^{6}$ Pain and Palliative Care Unit, Soroka Medical Center and Clalit Health Services, Beer-Sheva, Israel. ${ }^{7}$ Department of Public Health, Faculty of Health Sciences, Ben-Gurion University of the Negev, Beer-Sheva, Israel. ${ }^{8}$ Psychiatry Research Unit, Faculty of Health Sciences, Ben-Gurion University of the Negev and Mental Health Center, Beer-Sheva, Israel. ${ }^{9}$ These authors jointly supervised this work: Yuly Bersudsky and Abed N. Azab. ${ }^{10}$ Pnina Romem is deceased. ${ }^{凶}$ email: azab@ bgu.ac.il
} 
for depression are pharmacotherapy, electroconvulsive therapy and cognitive behavioral therapy ${ }^{1,2,7-10}$. However, despite the availability of therapeutic approaches, a high percentage of subjects with depression respond poorly, or not at all to administered treatments, with considerable amounts of them suffering unwanted side effects ${ }^{1,2,11}$. Importantly, few novel therapeutic interventions have been developed and introduced to clinical practice for the treatment of depression in recent years ${ }^{12-14}$. These data reinforce the need for a relentless search for novel efficacious and safe treatment options for depression.

Abnormal cellular energy metabolism due to functional deficiency in oxygen supply and/or mitochondrial dysfunction may lead to alterations in neuronal function, plasticity and brain circuitry. In a comprehensive review, Shao et al. ${ }^{15}$ summarized the evidence for the involvement of cellular energy metabolism abnormalities and mitochondrial dysfunction in psychiatric disorders and suggested that new treatment approaches should be directed to this research endeavor. Particularly, several studies reported mitochondrial function abnormalities in subjects with depression ${ }^{16-18}$.

Transfer of oxygen to the tissues in the human body depends almost entirely on the level and function of hemoglobin in the blood. Since almost all oxygen in the blood is bound to the hemoglobin molecule, only a tiny fraction is dissolved in plasma. Therefore, increasing the oxygen content in the air (at normobaric conditions) does not significantly increase the amount of oxygen carried to tissues, except in patients with respiratory disorders. These elements of basic physiology have discouraged studies on increasing the fraction of inspired oxygen under normal pressure in depression, as well as other neurological disorders. However, some studies suggested that the partial oxygen pressure $\left(\mathrm{PO}_{2}\right)$ in the plasma of brain capillaries may be a physiological parameter that is not necessarily related to the oxygen carrying capacity in the blood (by hemoglobin) ${ }^{19-21}$. For instance, Menzel et al. ${ }^{19}$ reported that normobaric hyperoxia treatment (increasing the percentage of oxygen in inspired air above $21 \%$ ) increased oxygen partial pressure in brain tissue, leading to improved mitochondrial function. More likely, the mechanisms of normobaric hyperoxia are complex, affecting various genes at a time and in a dose-dependent manner ${ }^{22}$. It is hypothesized that raising the pressure of the dissolved oxygen portion of the plasma affects oxygen pressure at key enzymes, perhaps in the mitochondria.

Normobaric oxygen treatment at a concentration of $40 \%$ was found safe in animal and human studies without evidence of pulmonary oxygen toxicity or neurological abnormalities ${ }^{23}$. On the other hand, the use of maximally high inspired oxygen percentage $\left(100 \% \mathrm{O}_{2}\right)$ was found to reduce cerebral blood flow ${ }^{24}$. Studies using normobaric hyperoxia as treatment for some neuropathological conditions ${ }^{25-27}$ have shown positive results. Our previous study in patients with schizophrenia ${ }^{28}$ had encouraged us to conduct a similar study in patients with depression. Thus, the objective of the present study was to examine the effect of normobaric oxygen treatment (35\% $\mathrm{O}_{2}$ ) on patients with depression. The fraction of inspired oxygen $\left(\mathrm{FiO}_{2}\right), 35 \%$, was decided based on the positive therapeutic effects observed in our study in patients with schizophrenia ${ }^{28}$ and the results of human studies demonstrating that $\mathrm{FiO}_{2}$ in the range between $~ 30-70 \%$ evinced positive safety outcomes ${ }^{28-30}$.

In contrast to normobaric oxygen treatment, hyperbaric oxygen treatment may entail significant dangers ${ }^{31-34}$, and is possible only for short albeit repeated exposures. The definition of hyperbaric oxygen treatment is the administration of $100 \%$ oxygen under increased atmospheric pressure. This intervention can definitively increase the oxygen carrying capacity of blood to the brain. Efficacious use was reported in transient cerebral ischemia and in multiple sclerosis ${ }^{35,36}$. Efrati et al. ${ }^{37}$ found that hyperbaric oxygen treatment could activate neuroplasticity in patients with chronic neurologic deficiencies due to stroke. Hyperbaric oxygen treatment was also reported to improve post-concussion syndrome years after mild traumatic brain injury ${ }^{38}$. However, a major limitation of hyperbaric oxygen treatment is its high cost-it requires a special chamber which is expensive and available only in select major medical centers around the world. The treatment process is of approximately an hour duration requiring patients to travel to a specific, often remote, location. Furthermore, it can have severe side effects if the pressure rises too quickly or decreases too rapidly. Therefore, given the preceding obstacles surrounding hyperbaric oxygen treatment, we hypothesized the possibility that normobaric oxygen treatment may serve as a useful and attractive treatment strategy for depression.

\section{Results}

Fifty five subjects with mild to moderate depression were recruited between 2014 and 2019 and randomized to receive treatment with oxygen-enriched air $\left(35 \% \mathrm{O}_{2}\right)$ for 1 month or room air $\left(21 \% \mathrm{O}_{2}\right)$ for 1 month. Medications were not changed in patients who were enrolled to the study. Demographic and clinical characteristics of participants are summarized in Table 1. Figure 1 illustrates the flow diagram of recruitment, acceptance and assignment to the study groups. Fifty-one participants completed the study interventions and were included in the final analysis. Twenty-nine received oxygen-enriched air and twenty-two received room air. Four participants who completed less than 2 weeks (one-oxygen-treated, three-air-treated) were not included in the analysis.

Effects of oxygen treatment on Hamilton Rating Scale for Depression (HRSD) score. Table 2 and Fig. 2 show the effect of oxygen treatment versus room air (control) on HRSD score in 51 patients with mild to moderate depression who completed the 1-month study. Oxygen treatment led to a significant reduction in HRSD total score compared with the control group (mean \pm standard deviation [SD], $10.5 \pm 4.2$ vs. 13.8 \pm 3.7 ) (Table 2). The mean \pm SD changes in the scores from baseline to week four were $-4.2 \pm 0.3$ points in the oxygentreated group and $-0.7 \pm 0.6$ in the control group, for a between-group difference of 3.5 points (95\% confidence interval [CI] -5.95 to $-1.0 ; \mathrm{P}=0.007$ ) (Fig. 2). The point estimate of the mean treatment effect on HRSD score was $2.745,95 \%$ CI $[1.167,4.323]$. We tested the influence of the following variables: age, gender, marital status, education levels, adherence to treatment, and age of onset of depressive illness-on the effect of oxygen treatment on HRSD score. Only age of onset of depression had a significant effect $(\mathrm{F}(12,42)=3.95$, Prob $>\mathrm{F}=0.0004)$; a younger age of onset was associated with a more severe depression (higher HRSD score). However, the beneficial 


\begin{tabular}{|c|c|c|}
\hline \multirow[b]{2}{*}{ Characteristic $^{\mathrm{a}}$} & \multicolumn{2}{|l|}{ Mean (SD) } \\
\hline & $\mathrm{O}_{2} 35 \%(\mathrm{n}=30)$ & $\mathrm{O}_{2} 21 \%(\mathrm{n}=25)$ \\
\hline Age, year & $47.4(11.2)$ & $43.9(13.5)$ \\
\hline Age onset depression, year & $35.83(13.63)$ & $33.24(12.20)$ \\
\hline Duration of illness, year & $(9.85) 11.63$ & (7.45) 10.44 \\
\hline Body mass index & $25.39(3.84)$ & $24.50(3.27)$ \\
\hline \multicolumn{3}{|l|}{ Baseline score } \\
\hline HRSD & $14.7(3.9)$ & $14.5(3.1)$ \\
\hline CGI-S & $3.37(0.49)$ & $3.3(0.46)$ \\
\hline WHO-5-QOL score & $6.89(4.35)$ & $6.87(4.66)$ \\
\hline SDS score & $20.1(7.0)$ & $20.6(6.2)$ \\
\hline \multirow[t]{2}{*}{ Arterial hemoglobin-oxygen saturation, $\%$} & $96.95(0.84)$ & $97.18(0.52)$ \\
\hline & \multicolumn{2}{|l|}{$\mathrm{N}(\%)^{\mathrm{b}}$} \\
\hline \multicolumn{3}{|l|}{ Depression severity at baseline $^{c}$} \\
\hline Mild depression & $18(60.0)$ & $18(72.0)$ \\
\hline Moderate depression & $12(40.0)$ & $7(28.0)$ \\
\hline \multicolumn{3}{|l|}{ Gender } \\
\hline Female & $17(56.6)$ & $14(56.0)$ \\
\hline Male & $13(43.3)$ & $11(44.0)$ \\
\hline \multicolumn{3}{|l|}{ Employment status } \\
\hline Employed/partially employed & $20(66.7)$ & $13(52.0)$ \\
\hline Unemployed & $8(26.7)$ & $9(36.0)$ \\
\hline Pensioned & $1(3.3)$ & $0(0.0)$ \\
\hline Student & $1(3.3)$ & $3(12.0)$ \\
\hline \multicolumn{3}{|l|}{ Marital status } \\
\hline Married & $19(63.3)$ & $10(40.0)$ \\
\hline Divorced & $8(26.7)$ & $6(24.0)$ \\
\hline Single & $2(6.7)$ & $8(32.0)$ \\
\hline Widowed & $1(3.3)$ & $1(4.0)$ \\
\hline \multicolumn{3}{|l|}{ Educational level } \\
\hline High school & $10(33.3)$ & $14(56.0)$ \\
\hline College or university & $20(66.7)$ & $11(44.0)$ \\
\hline \multicolumn{3}{|l|}{ Ethnic geographic origin } \\
\hline Ashkenazic & $15(50.0)$ & $9(36.0)$ \\
\hline Sephardic & $14(46.7)$ & $15(60.0)$ \\
\hline Arab & $1(3.3)$ & $0(0)$ \\
\hline Other & $0(0)$ & $1(4.0)$ \\
\hline \multicolumn{3}{|l|}{ Cigarette smoking } \\
\hline No & $15(50.0)$ & $16(64.0)$ \\
\hline Yes & $15(50.0)$ & $9(36.0)$ \\
\hline \multicolumn{3}{|l|}{ Underlying physical disorders $^{\mathrm{d}}$} \\
\hline No & $15(50.0)$ & $8(32.0)$ \\
\hline Yes & $15(50.0)$ & $17(68.0)$ \\
\hline \multicolumn{3}{|l|}{ Family history of psychiatric illness ${ }^{\mathrm{e}}$} \\
\hline No & $18(60.0)$ & $16(64.0)$ \\
\hline Yes & $15(40.0)$ & $9(36.0)$ \\
\hline \multicolumn{3}{|l|}{ Previous use of antidepressant medication } \\
\hline No & $9(30.0)$ & $6(24.0)$ \\
\hline Yes & $21(70.0)$ & $19(76.0)$ \\
\hline \multicolumn{3}{|c|}{ Antidepressant medication use at recruitment ${ }^{f}$} \\
\hline No & $11(36.7)$ & $11(44.0)$ \\
\hline Yes & $19(63.3)$ & $14(56.0)$ \\
\hline
\end{tabular}

Table 1. Demographic and clinical characteristics of recruited participants at baseline. CGI-S Clinical Global Impression-severity, HRSD Hamilton rating scale for depression, $S D$ standard deviation, SDS Sheehan disability scale, SOC sense of coherence, $W H O-5-Q O L$ world health organization-5 quality of life (questionnaire). ${ }^{a}$ Using $T$-test or chi-square test (according to type of parameter), there were no significant differences between the groups in any of the tested parameters. ${ }^{b}$ Percent in $35 \% \mathrm{O}_{2}$-treated or $21 \% \mathrm{O}_{2}$-treated groups. ${ }^{c}$ Depression severity based on Clinical Global Impression: mild-2-3, moderate-4. ${ }^{\mathrm{d}}$ Including the following diseases: Attention deficit hyperactive disorder, fibromyalgia, hypothyroidism, cancer, anemia, eye disorder, heart disease, psoriasis, stomach/peptic disease,

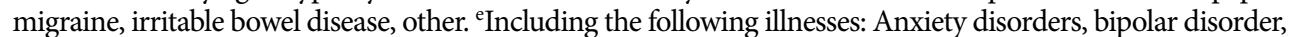
depressive disorder, mental retardation, obsessive-compulsive disorder, posttraumatic stress disorder, schizophrenia,

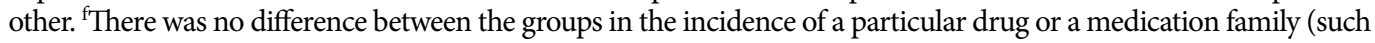
tricyclic antidepressants or selective serotonin reuptake inhibitors). 
410 subjects were assessed for eligibility and underwent initial screening

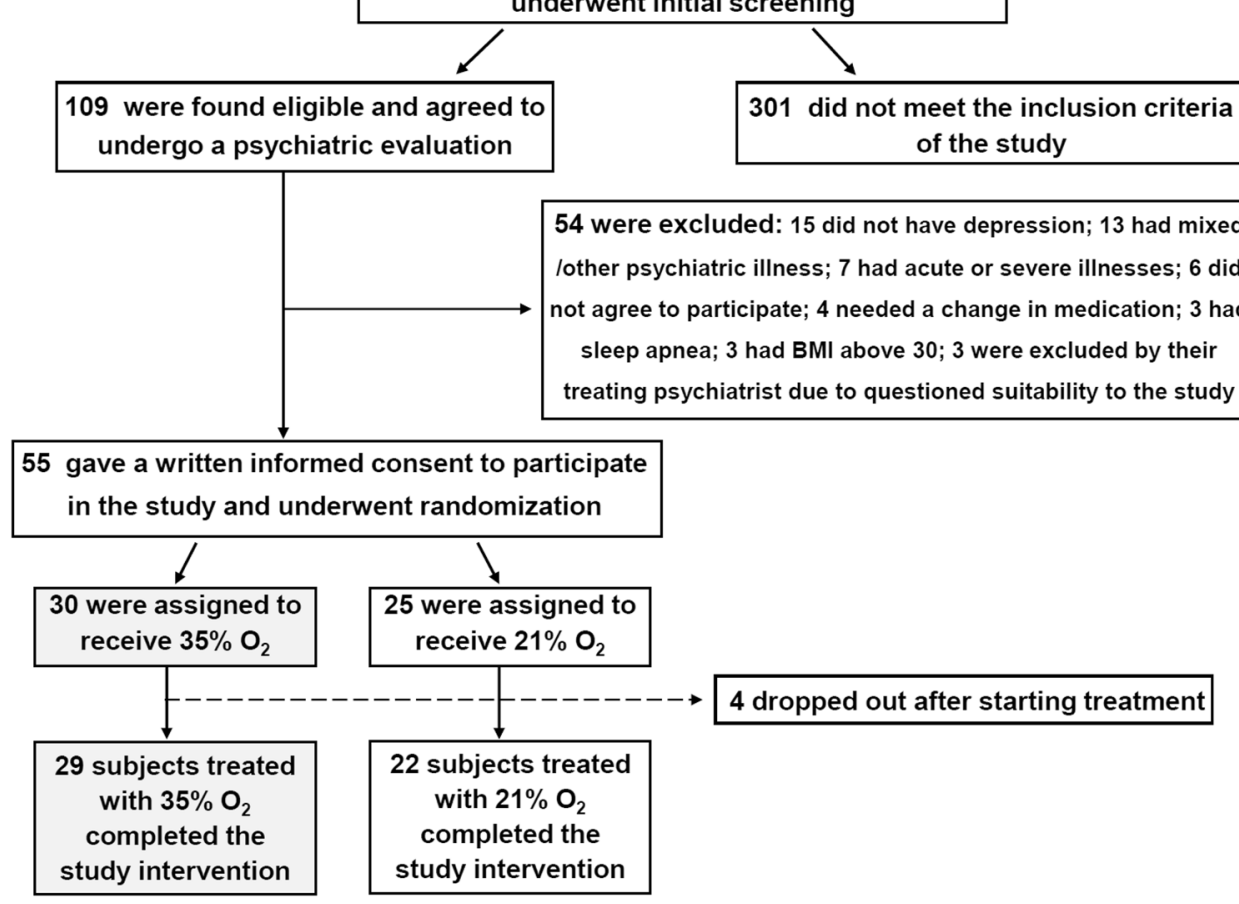

Figure 1. Screening and enrollment to the study. BMI denotes body mass index.

\begin{tabular}{|l|l|l|l|l|}
\hline Measure & Treatment & Baseline $($ mean \pm SD $)$ & Week 2 $($ mean \pm SD $)$ & Week 4 $($ mean \pm SD $)$ \\
\hline \multirow{2}{*}{ HRSD } & $35 \% \mathrm{O}_{2}(\mathrm{n}=29)$ & $14.7 \pm 3.9$ & $12.5 \pm 4.7$ & $10.5 \pm 4.2$ \\
\cline { 2 - 5 } & $21 \% \mathrm{O}_{2}(\mathrm{n}=22)$ & $14.5 \pm 3.1$ & $14.1 \pm 3.6$ & $13.8 \pm 3.7$ \\
\hline \multirow{2}{*}{ CGI-I } & $35 \% \mathrm{O}_{2}(\mathrm{n}=29)$ & & $3.4 \pm 0.68$ & $3.13 \pm 0.74$ \\
\cline { 2 - 5 } & $21 \% \mathrm{O}_{2}(\mathrm{n}=22)$ & & $3.7 \pm 0.53$ & $3.77 \pm 0.43$ \\
\hline \multirow{2}{*}{ WHO-5-QOL } & $35 \% \mathrm{O}_{2}(\mathrm{n}=29)$ & $6.89 \pm 4.35$ & $9 \pm 5.2$ & $11.4 \pm 4.85$ \\
\cline { 2 - 5 } & $21 \% \mathrm{O}_{2}(\mathrm{n}=22)$ & $6.87 \pm 4.66$ & $8.4 \pm 6.2$ & $9.5 \pm 6.097$ \\
\hline \multirow{2}{*}{ SOC-13 } & $35 \% \mathrm{O}_{2}(\mathrm{n}=29)$ & $50.13 \pm 12.33$ & $53.13 \pm 13.7$ & $57.3 \pm 9.16$ \\
\cline { 2 - 5 } & $21 \% \mathrm{O}_{2}(\mathrm{n}=22)$ & $46.8 \pm 8.79$ & $50.5 \pm 8.2$ & $53.0 \pm 11.73$ \\
\hline \multirow{2}{*}{ SDS } & $35 \% \mathrm{O}_{2}(\mathrm{n}=29)$ & $20.1 \pm 7.0$ & $16.8 \pm 7.0$ & $14.4 \pm 7.6$ \\
\cline { 2 - 6 } & $21 \% \mathrm{O}_{2}(\mathrm{n}=22)$ & $20.6 \pm 6.2$ & $19.9 \pm 7.0$ & $19.0 \pm 8.0$ \\
\hline
\end{tabular}

Table 2. Effect of oxygen treatment on study outcomes. CGI-I clinical global impression-improvement, CI confidence interval, HRSD Hamilton rating scale for depression, SD standard deviation, SDS Sheehan disability scale, SOC sense of coherence, WHO-5-QOL world health organization-5 quality of life (questionnaire).

therapeutic effect of oxygen treatment on HRSD score remained significant even after correction for this variable. Importantly, age of onset of depression did not differ significantly between the groups at baseline (Table 1). Other variables such as cigarette smoking status, body mass index, depressive illness duration, and use and type of antidepressant medications at recruitment did not have a significant effect on the results.

Table 3 shows the multivariate regression analysis for the HRSD sub-scale factors. The reduction in the overall score of HRSD due to oxygen treatment was significantly due to the positive effect on factor 1 - anxiety/somatization ( $95 \% \mathrm{CI}-2.24$ to $-0.51 ; \mathrm{P}=0.003)$, and factor 3 -cognitive disturbance $(95 \% \mathrm{CI}-1.66$ to $-0.28 ; \mathrm{P}=0.007)$. Together, these factors led to nearly $53 \%$ of the total change in HRSD score; factor 1 accounted for $~ 29 \%$ of the total reduction in HRSD and factor 3 accounted for $\sim 24 \%$ of the total reduction in HRSD. The change in the other factors was not statistically significant (Table 3). However, all the other items except diurnal variation were nominally more improved by oxygen treatment than room air. Many studies suggested that remission should be defined with a HRSD cut-off of seven or less ${ }^{39-41}$. Using that criterion, we found seven patients who reached remission with oxygen treatment and no patients in the control group who reached remission. 


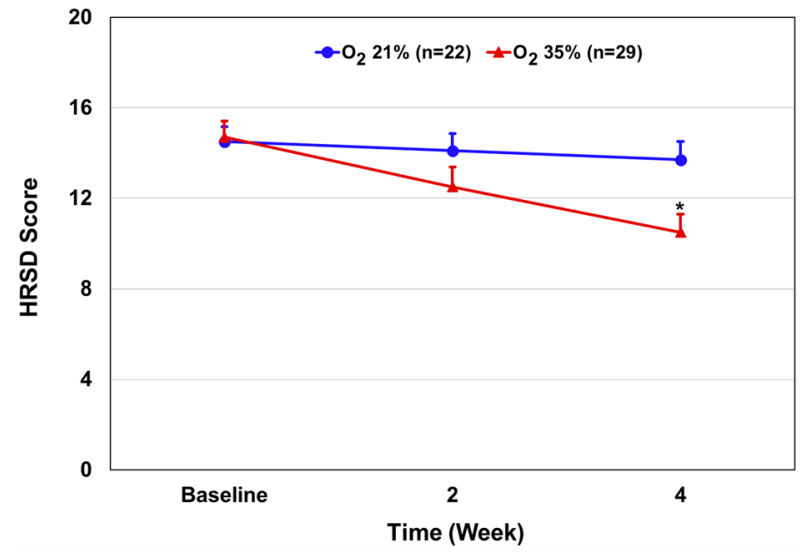

Figure 2. Effect of $35 \%$ oxygen treatment on total HRSD score. Results are presented as mean \pm SEM. ${ }^{*}$ Multivariate regression analysis: The mean \pm SD changes in the scores from baseline to week four were $-4.2 \pm 0.3$ points in the oxygen-treated group and $-0.7 \pm 0.6$ in the control group, for a between-group difference of 3.5 points $(95 \%$ confidence interval $[\mathrm{CI}]-5.95$ to $-1.0 ; \mathrm{P}=0.007)$.

\begin{tabular}{|c|c|c|c|c|c|}
\hline \multirow[b]{2}{*}{ HRSD subscale factor } & \multirow[b]{2}{*}{$\mathrm{O}_{2} \%$} & \multicolumn{2}{|c|}{ Mean \pm SD } & \multicolumn{2}{|l|}{ Between group effect } \\
\hline & & Baseline & Week 4 & Baseline & Week 4 \\
\hline \multirow{2}{*}{ \#1-Anxiety/somatization } & $35 \% \mathrm{O}_{2}$ & $3.96 \pm 1.5$ & $2.75 \pm 1.5$ & \multirow{2}{*}{$95 \% \mathrm{CI}-0.95$ to $0.78 ; \mathrm{P}=0.85$} & \multirow{2}{*}{$95 \% \mathrm{CI}-2.24$ to $-0.51 ; \mathrm{P}=0.003^{*}$} \\
\hline & $21 \% \mathrm{O}_{2}$ & $4.04 \pm 1.4$ & $4.09 \pm 1.3$ & & \\
\hline \multirow{2}{*}{$\# 2$-Weight } & $35 \% \mathrm{O}_{2}$ & $1.2 \pm 0.8$ & $0.6 \pm 0.7$ & \multirow{2}{*}{$95 \% \mathrm{CI}-0.39$ to $0.53 ; \mathrm{P}=0.76$} & \multirow{2}{*}{$95 \% \mathrm{CI}-0.87$ to $-0.01 ; \mathrm{P}=0.045$} \\
\hline & $21 \% \mathrm{O}_{2}$ & $1.1 \pm 0.7$ & $1.0 \pm 0.7$ & & \\
\hline \multirow{2}{*}{ \#3-Cognitive disturbance } & $35 \% \mathrm{O}_{2}$ & $2.5 \pm 1.4$ & $1.5 \pm 1.3$ & \multirow{2}{*}{$95 \% \mathrm{CI}-0.99$ to $0.51 ; \mathrm{P}=0.52$} & \multirow{2}{*}{$95 \% \mathrm{CI}-1.66$ to $-0.28 ; \mathrm{P}=0.007^{*}$} \\
\hline & $21 \% \mathrm{O}_{2}$ & $2.8 \pm 0.9$ & $2.5 \pm 0.9$ & & \\
\hline \multirow{2}{*}{ \#4-Diurnal variation } & $35 \% \mathrm{O}_{2}$ & $0.9 \pm 0.7$ & $0.7 \pm 0.6$ & \multirow{2}{*}{$95 \% \mathrm{CI}-0.74$ to $0.74 ; \mathrm{P}=0.11$} & \multirow{2}{*}{$95 \% \mathrm{CI}-0.25$ to $0.45 ; \mathrm{P}=0.56$} \\
\hline & $21 \% \mathrm{O}_{2}$ & $0.7 \pm 0.6$ & $0.6 \pm 0.5$ & & \\
\hline \multirow{2}{*}{ \#5-Retardation } & $35 \% \mathrm{O}_{2}$ & $4.0 \pm 1.1$ & $3.3 \pm 1.2$ & \multirow{2}{*}{$95 \% \mathrm{CI}-0.63$ to $0.79 ; \mathrm{P}=0.83$} & \multirow{2}{*}{$95 \% \mathrm{CI}-1.32$ to $0.09 ; \mathrm{P}=0.086$} \\
\hline & $21 \% \mathrm{O}_{2}$ & $4.0 \pm 1.1$ & $3.9 \pm 1.1$ & & \\
\hline \multirow{2}{*}{ \#6-Sleep disturbance } & $35 \% \mathrm{O}_{2}$ & $2.8 \pm 2.1$ & $1.8 \pm 1.7$ & \multirow{2}{*}{$95 \% \mathrm{CI}-0.90$ to $1.27 ; \mathrm{P}=0.74$} & \multirow{2}{*}{$95 \% \mathrm{CI}-1.53$ to $0.46 ; \mathrm{P}=0.29$} \\
\hline & $21 \% \mathrm{O}_{2}$ & $2.6 \pm 1.7$ & $2.4 \pm 1.8$ & & \\
\hline
\end{tabular}

Table 3. Effect of oxygen treatment on HRSD sub-scale factors improvement. CI confidence interval, $H R S D$ Hamilton rating scale for depression, $S D$ standard deviation. ${ }^{\star} \mathrm{P}<0.008$ (significant).

Effects of oxygen treatment on Clinical Global Impression (CGI) score. Table 2 and Fig. 3 show the effect of oxygen treatment on CGI improvement score. Oxygen treatment led to a significant reduction in CGI score compared with room air (mean \pm SD, $3.13 \pm 0.74$ vs. $3.77 \pm 0.43$ ) (Table 2). At week four, there was a between-group difference of 0.71 points $(95 \% \mathrm{CI}-1.00$ to $-0.29 ; \mathrm{P}=0.001)$. The point estimate of the mean treatment effect on CGI score was $-0.078,95 \%$ CI $[-0.313,0.156]$. Of note, the variable "age of onset of depression" did not have a significant effect on CGI-I score $(F(18,42)=1.66$, Prob $>F=0.0888)$. There were significantly more improved patients in the oxygen treatment as opposed to the control group, as measured by CGI (Fig. 3; Chi-square 11.5, df $=3, \mathrm{P}<0.01$ ).

Effects of oxygen treatment on the World Health Organization-5 Well-being Index for estimation of Quality of Life (WHO-5-OOL) score. There was no significant difference in the WHO-5-QOL score between the groups after 4 weeks of oxygen versus room air treatment (mean \pm SD, $11.4 \pm 4.85$ vs. $9.5 \pm 6.1$ ) (Table 2). The mean \pm SD changes in the scores from baseline to week four were $4.5 \pm 0.5$ points in the oxygentreated group and $2.6 \pm 1.44$ in the control group, for a between-group difference of 1.9 points $(95 \% \mathrm{CI}-1.08$ to 1.86; $\mathrm{P}=0.597$ ) (Fig. 4).

Effects of oxygen treatment on the Sense of Coherence (SOC)-13 score. There was no significant difference in SOC-13 score between the groups after 4 weeks of oxygen versus room air treatment (mean \pm SD, $57.3 \pm 9.16$ vs. $53.0 \pm 11.73$ ) (Table 2). The mean \pm SD changes in the scores from baseline to week four were $7.2 \pm 3.7$ points in the oxygen-treated group and $6.2 \pm 2.9$ in the control group, for a between-group difference of 0.97 points ( $95 \% \mathrm{CI}-3.18$ to 9.99 ; $\mathrm{P}=0.303$ ) (Fig. 5). 


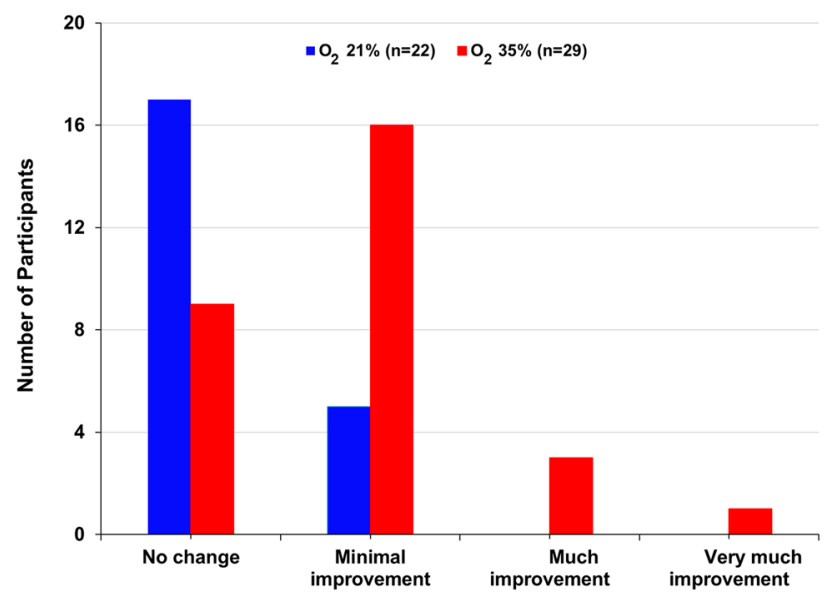

Figure 3. Effect of $35 \%$ oxygen treatment on CGI improvement score at 4 weeks. The data are presented as the change from baseline to week four. There were significantly more improved patients in the $35 \%$ oxygen treatment group as opposed to the control group, as measured by CGI improvement (Chi-square $11.5, \mathrm{df}=3$, $\mathrm{P}<0.01)$.

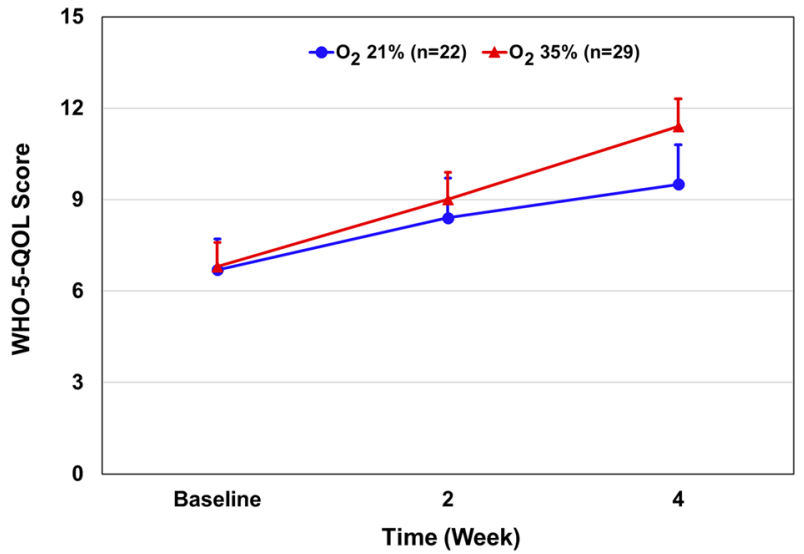

Figure 4. Effect of $35 \%$ oxygen treatment on WHO-5QOL score. Results are presented as mean \pm SEM. Multivariate regression analysis: The mean \pm SD changes in the scores from baseline to week four were $4.5 \pm 0.5$ points in the oxygen-treated group and $2.6 \pm 1.44$ in the control group, for a between-group difference of 1.9 points $(95 \% \mathrm{CI}-1.08$ to $1.86 ; \mathrm{P}=0.597)$.

Effects of oxygen treatment on Sheehan Disability Scale (SDS) score. There was no significant difference in SDS score between the groups after 4 weeks of oxygen versus room air treatment (mean \pm SD, $14.4 \pm 7.6$ vs. $19.0 \pm 8.0$ ) (Table 2 ). The mean \pm SD changes in the scores from baseline to week four were $-5.7 \pm 0.6$ points in the oxygen-treated group and 1.6 \pm 2.2 in the control group, for a between-group difference of 4.1 points (95\% CI -9.84 to $0.22 ; \mathrm{P}=0.06$ ) (Fig. 6). Thus, oxygen treatment trended a positive although non-significant effect on coping ability among oxygen-treated subjects.

Tolerability. Side effects were assessed in all participants at 2 and 4 weeks after treatment initiation. The double-blind treatment was well tolerated in both groups. Four participants dropped-out of the study: one oxygentreated and three air-treated. Reasons for drop-out: One participant was not interested in continuing without giving a particular reason; two participants were bothered by the noise arriving from the oxygen generator; and, one participant complained of dizziness. Thus, only one patient reported an adverse event-dizziness-which he associated to the treatment he received. To note, this patient was treated with the placebo (room air).

\section{Discussion}

The present study examined the effect of normobaric oxygen treatment $\left(\sim 35 \% \mathrm{O}_{2}\right)$ on symptoms of subjects with depression. Oxygen treatment resulted in a significant reduction in HRSD total score and benefit in the CGI score, without causing significant side effects. These findings deserve replication and future study. The severity of the symptoms of depression was examined using the HRSD scale. Results showed that oxygen therapy significantly 


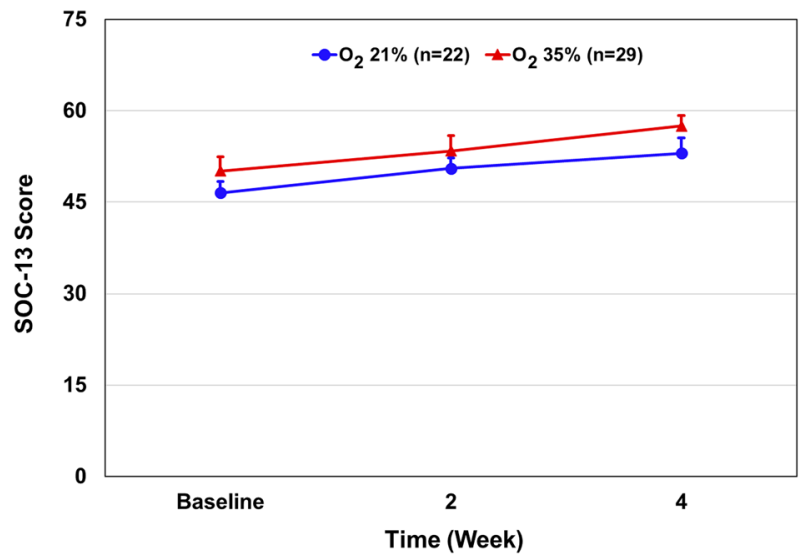

Figure 5. Effect of $35 \%$ oxygen treatment on SOC-13 score. Results are presented as mean \pm SEM. Multivariate regression analysis: The mean \pm SD changes in the scores from baseline to week four were $7.2 \pm 3.7$ points in the oxygen-treated group and $6.2 \pm 2.9$ in the control group, for a between-group difference of 0.97 points (95\% CI -3.18 to $9.99 ; \mathrm{P}=0.303)$.

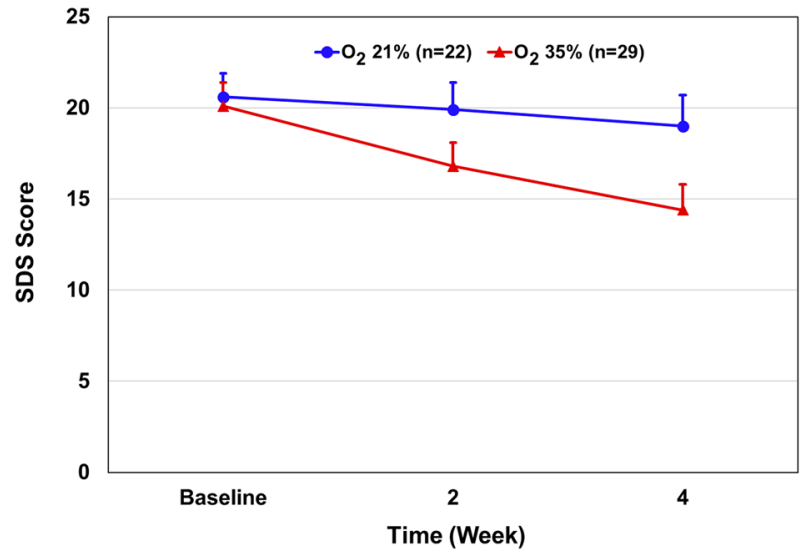

Figure 6. Effect of $35 \%$ oxygen treatment on SDS score. Results are presented as mean \pm SEM. Multivariate regression analysis: The mean \pm SD changes in the scores from baseline to week four were $-5.7 \pm 0.6$ points in the oxygen-treated group and $1.6 \pm 2.2$ in the control group, for a between-group difference of 4.1 points (95\% CI -9.84 to $0.22 ; \mathrm{P}=0.06)$.

reduced the overall HRSD value by four points in 29 patients after 1 month of treatment (Table 2 and Fig. 2). There was a difference of 3.5 points in HRSD between the two groups. A multivariate regression analysis of the HRSD sub-scale factors revealed that the improvement in HRSD score in oxygen-treated subjects was mainly due to a significant reduction in factor 1 -anxiety/somatization $(\mathrm{P}=0.003)$ and factor 3 -cognitive disturbance $(\mathrm{P}=0.007)$, compared with the absence of significant effects on the other parts of the HRSD factors (Table 3$)$. The effect of oxygen treatment on CGI score was also examined. At 4 weeks, the CGI score was significantly lower $(\mathrm{P}=0.001)$ in the oxygen-treated group as compared to the control group, with 0.7 points difference between the two groups (Table 2). Consistently, $69 \%$ of the patients in the oxygen treatment group improved compared with $\sim 23 \%$ in the control group (Fig. 3). Moreover, oxygen treatment non-significantly $(\mathrm{P}=0.06)$ attenuated the disability score as measured by SDS (Table 2 and Fig. 4), suggesting that it may improve the coping ability of participants. In contrast, oxygen treatment did not improve the general well-being (WHO-5-QOL) and did not increase the SOC score of treated subjects.

The positive effects of oxygen therapy on depression symptoms were achieved within 1 month of treatment. A significant difference between the oxygen treatment group and the control group was demonstrable only after four continues weeks of oxygen therapy. It is possible that a more significant improvement could be achieved if oxygen treatment were to be administered for a longer period of time. Thus, future studies should examine whether a longer treatment duration results in a more significant oxygen treatment effect. Moreover, the present study included outpatients of mild to moderate depression severity. It would be interesting to test the causatum of oxygen treatment among different levels of depression severity, including in-hospital patients with severe depression. It should also be studied with different oxygen doses $\left(\mathrm{FiO}_{2}\right)$. The oxygen fraction could perhaps be increased up to $45 \%$ without incurring significant safety risks ${ }^{29,42}$. In this regard, the currently available data do 
not enable drawing unequivocal conclusions regarding the long-term safety of normobaric oxygen treatment among non-hypoxic subjects ${ }^{43}$. Early studies revealed that moderate normobaric oxygen treatment $\left(30-40 \% \mathrm{O}_{2}\right)$ was safe and did not cause adverse effects or signs of toxicity ${ }^{23}$. However, recent studies demonstrated conflicting results. For example, Stub et al. ${ }^{44}$ reported that normobaric oxygen treatment (oxygen via face mask at $8 \mathrm{~L} /$ $\mathrm{min}$ ) in non-hypoxic patients with ST-segment elevation myocardial infarction was associated with increased early myocardial injury and larger infarct size at 6 months post-myocardial infarction. A comprehensive metaanalysis study revealed that liberal administration of oxygen in non-hypoxic acutely ill patients was associated with significantly increased mortality ${ }^{45}$. However, this meta-analysis included many trials in which the oxygen treatment was given at a relatively high fraction of inspired oxygen $\left(\mathrm{FiO}_{2} 80-100 \%\right)$. In contrast, Hofmann et al. ${ }^{46}$ tested the efficacy and safety of normobaric oxygen treatment (oxygen via face mask at $6 \mathrm{~L} / \mathrm{min}$ ) in non-hypoxic patients with acute myocardial infarction. They found that the treatment was not associated with harmful effects, including absence of increased early myocardial injury. Moreover, a large-scale randomized clinical trial in acute stroke patients showed that oxygen treatment $\left(\mathrm{FiO}_{2} 30 \%\right)$ was not associated with any significant adverse effects $^{30}$. This study also showed that nocturnal oxygen treatment $(10 \mathrm{~h}$ per night $)$ was associated with better safety outcomes as compared to continuous ( $24 \mathrm{~h}$ per day) oxygen treatment. This is pertinent to the design of the present study because we also administered oxygen treatment only during the night, for approximately $7 \mathrm{~h}$ per night. Other studies showed that even oxygen treatment of a high fraction of inspired oxygen is safe and possibly effective in severely ill patients ${ }^{42,47,48}$.

As to the tolerability of oxygen treatment, the present study demonstrated that it is safe and did not lead to side effects. Two patients dropped out of the study due to the noise produced by the oxygen generator. If oxygen therapy becomes more common among patients with depression, the problem of noise from the oxygen device can easily be overcome by connecting patients to an oxygen container as a source of oxygen, similar to the one used for respiratory problems. In the present study, patients received a 7.5-m long nasal-tube. For most of them, this allowed for placement of the machine at a far enough distance so as not to be disturbed by the noise. There were also patients who conversely mentioned that the machine's noise helped them sleep. The oxygen generator used in this study weighed $24.5 \mathrm{~kg}$. Previous studies reported that some patients perceived a decrease in quality of life due to their described experience of oxygen generators being heavy and cumbersome ${ }^{49}$. Today this obstacle can be easily defeated as there are smaller units, even portable. Although more expensive, smaller units may facilitate the transportation to and from the patient's home. Some subjects reported that they would willingly pay for portable oxygen systems out-of-pocket because of the mobility it provides ${ }^{49}$. Portable oxygen devices simplify and impel patient therapy; subjects preferred using a portable oxygen systems both at home and during ambulation $^{50}$.

The present study did not explore the biological mechanism underpinning the beneficial effects of normobaric oxygen treatment in subject with depression. As mentioned, improvement of mitochondrial function ${ }^{19}$ may contribute to therapeutic effects of normobaric hyperoxia. Normobaric hyperoxia has been reported to influence the function of numerous cellular pathways in the brain, including oxygen sensing mechanisms, pro-survival pathways such as protein kinase B (Akt), mitogen-activated protein kinases, neurotrophins such as brain-derived neurotrophic factor, erythropoietin and its receptors, neuroglobin, nitric oxide, and carbon monoxide ${ }^{22}$. Albeit through different mechanisms, studies in patients with post-stroke depression have shown that hyperbaric oxygen treatment reduces the severity of depression symptoms ${ }^{51,52}$. In animals, hyperbaric oxygen treatment was associated with beneficial neuroprotective effects following brain insults such as traumatic brain injury ${ }^{53}$ and focal cerebral ischemi ${ }^{54}$. These studies revealed that hyperbaric oxygen treatment exerts anti-neuroinflammatory effects including an increment of brain levels of the anti-inflammatory cytokine interleukin (IL)-10 ${ }^{53}$ and a reduction in brain levels of the pro-inflammatory cytokines IL- $1 \beta$ and tumor necrosis factor- $\alpha$, and, a decrease in myeloperoxidase activity ${ }^{54}$.

Our statistical analyses clearly demonstrated that the positive therapeutic effects of oxygen treatment did not derive from differences in the rate of adherence to treatment between the groups. Namely, the multivariate regression analysis revealed that the variable "adherence to treatment" (as measured by average exposure time to the treatment regimens) did not have a significant influence on the effect of oxygen treatment on HRSD score ( $95 \%$ CI -0.0695 to 0.0056; P = 0.093). Similarly, all other tested outcomes (CGI, SDS, WHO-5-QOL, and SOC13 scores) were not affected by adherence to treatment. Moreover, the positive effects were not due to differences in basic or clinical characteristics of participants. Interestingly, current antidepressant drugs do not have a mood elevating effect in normal persons, whereas drugs like amphetamines do. We speculate that the oxygen treatment exerts an antidepressant effect rather than a mood-elevating effect. A study of normal volunteers given normobaric oxygen treatment has not yet been done and would be an important study to do in the future. "Oxygen bars" have become popular in Japan and other East Asian countries, said to generate mood elevating effects s $^{55}$. In an effort to unveil this unknown, normal volunteers might be studied with normobaric oxygen treatment administered during a night sleep and consequently exploring a possible elevation in mood the following day.

One can compare the reduction in HRSD with oxygen treatment in the present study to that of patients

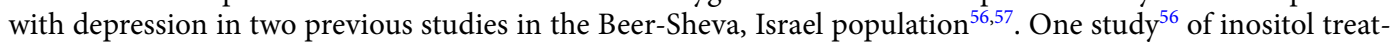
ment of depression was a double-blind trial; 13 patients were given inositol and 15 patients were given placebo. Over 4 weeks of treatment the HRSD score declined significantly more for those inositol treated than for the placebo. The mean reduction of HRSD in the patients receiving inositol was 10.8 points, compared to four points in the placebo group, a nearly seven-point difference. In another study ${ }^{57}$, omega-3 fatty acids treatment was given to a mixed group of patients, some taking antidepressants and some not, as in the present study. The mean reduction of HRSD score in the patients receiving omega- 3 fatty acids was 12.4 points, compared to 2.3 points in the placebo group, culminating in roughly a 10-point difference. In this regard, it is worth noting that recent meta-analysis studies have demonstrated much smaller effect sizes of omega-3 fatty acids ${ }^{58,59}$ as well as classic antidepressant drugs ${ }^{60,61}$ as a treatment for depression. In our study, the decline in HRSD over the course 
of 4 weeks was 4.2 points in the oxygen group and 0.7 points in the control group, about a 3.5-point difference. It is widely reported that the placebo-treatment difference in depression studies has markedly declined worldwide over the last 30 years ${ }^{62-64}$. Moreover, the Levine et al. ${ }^{56}$ and Nemets et al. ${ }^{57}$ studies recruited patients from an outpatient psychiatry clinic, whereas the current study recruited participants from family medicine clinics.

Limitations. The present study has several limitations. First, it included a relatively small sample size. However, a small sample is acceptable in pilot studies that investigate novel therapeutic interventions in psychiatric patients ${ }^{65-67}$. Second, this study did not explore the biological mechanism underlying the therapeutic effects of normobaric oxygen treatment on the brain. Third, we did not follow the patients after the last planned assessment ( 4 weeks), so we cannot speculate whether the observed relief in depressive symptoms is durable. Fourth, the external validity of the results is limited because the study was conducted in a particular group of patients; outpatients with mild to moderate depression who live in the southern district of Israel.

\section{Conclusions}

This pioneer, proof-of-concept, double-blind study showed that normobaric oxygen treatment is beneficial in patients with depression. These results require further examination and replication in future studies of larger cohorts. Given that normobaric oxygen treatment is a simple, not invasive and safe therapeutic intervention makes it a potential and attractive treatment for depression.

\section{Methods}

All methods in the study were carried out in accordance with relevant guidelines and regulations.

Study design and participants. This randomized, double-blind study lasted 4 weeks. Participants were recruited to the study through two routes: (1) subjects who directly contacted the investigators expressing interest in participating in the study following advertisement in public media; and, (2) subjects from Clalit Health Services in Beer-Sheva, Israel, who were referred to the study by their family physicians. An initial screening for depression was done by an experienced psychiatric nurse, using a questionnaire based on the Structured Clinical Interview for Depression ${ }^{68}$. Patients deemed suitable were interviewed by a board-certified psychiatrist in order to confirm Diagnostic and Statistical Manual of Mental Disorders-4 depression ${ }^{69}$ and approve participation in the study. Only participants who had a HRSD score $\geq 8$ and provided written informed consent to participate in the study were included. The cut-off of $\geq 8$ for the HRSD was based on data from previous studies ${ }^{39,70}$. Inclusion Criteria: Men and women aged 18-65 years with mild to moderate depression (HRSD score 8-18) ${ }^{39,70}$; and, blood oxygen saturation $\geq 95 \%$ at room air. Blood oxygen saturation at baseline was assessed using a high precision Pulse Oximeter (CONTEC Medical Systems Co., Ltd.; Shanghai, China). Exclusion Criteria: An unstable psychiatric condition; a need for change in current psychiatric medication prescriptions; suicidal ideations or suicide attempts at the time of recruitment; drug abuse; acute or chronic respiratory disease; any severe physical illness; obesity (body mass index [calculated as weight in kilograms divided by height in meters squared] $>30$ ); non-Hebrew speakers; or inability to cease smoking during night hours while participants were supposed to use the oxygen supplementing machine. Four hundred and ten subjects were assessed for suitability and underwent an initial screening (Fig. 1). Fifty five participants met the inclusion criteria of the study, signed an informed consent form to participate and underwent randomization (Fig. 1).

Sample size. During the planning phase of the study, we assumed that most of the participants we would recruit would already be on pharmaceutical antidepressant treatment (this estimate turned out to be correct; $60 \%$ of the study participants were on antidepressant treatment at baseline, Table 1), thus, the addition of oxygen/placebo treatment would serve as an "add-on" therapy. Published studies of add-on therapies in depressive patients have shown that there is a chance of gaining an additional 30 to $50 \%$ response in the add-on treatment groups $^{71,72}$. Based on these findings, we performed a power analysis using the following parameters: Two-sided significance level $=95 \%$; power $=80 \%$; desired ratio between the groups $1: 1$. The calculation revealed that we should recruit 40 subjects to each group ( 80 subjects in total for the trial). However, after initiating the trial, we came to know that it was very difficult to recruit participants to a study investigating a novel treatment strategy wherein the utility and tolerability of which are entirely unknown to enrollees. After 6 years of enrollment (2014-2019) and recruitment of 55 subjects, we consulted with our advising committee and jointly decided to discontinue recruitment. Our decision was based on two considerations: (1) The prolonged trial duration may influence the outcomes of the trial (time-effect), and, (2) a relatively small sample is acceptable in randomized clinical trials that investigate novel therapeutic interventions in psychiatric patients ${ }^{65-67}$.

Procedure and randomization. An oxygen generator is a portable unit that was easily translocated to the home bedside of participants. The machine supplies highly oxygen-enriched air (up to $99 \% \mathrm{O}_{2}$ ). By setting a flow rate of $5-6 \mathrm{~L} / \mathrm{min}^{73}, 35 \%$ oxygen is delivered to the lungs when nasal tubes are used (as in our study). Machines utilized in the control and intervention groups looked and sounded identical; it was not possible for field-researchers or participants to know which treatment each participant received. Machines used as controls were inactivated by disconnection of an internal pipeline that transfers oxygen, thereby impeding on the technological mechanism and resulting in air-crossing. The procedure was performed by a certified medical equipment laboratory of Clalit Health Services under the direction of the investigator who was in charge of generating the allocation sequence (Yu.Be.). This investigator was aware of the particular settings (treatment) of each machine and, therefore, was not involved or present in any assessment of study participants. He provided the coded 
machines to the field-researcher (Ye.Bl.) and she handed them to participants blinded to the treatment allocation. The safety and technical compatibility of the oxygen generators were monitored by a designated manufacturer's technician. The safety and compatibility evaluations of the machines were conducted after completion of every treatment course (up to 1 month treatment for individual patients) and included the following: assessment of machine completeness and general safety (e.g., power cord), cleaning of machine filters, inspection for air/ oxygen leaks, assurance of accurate oxygen supply (flow and $\mathrm{FiO}_{2}$ ). Patients were instructed not to smoke near the device. Participants were monitored by the research nurse who oversaw their safety and adherence and executed the rating scale assessments at designated time points. Subjects received a 7.5-m long oxygen tube allowing the machine to be placed at a convenient distance from their bed.

Study intervention. Consecutive participants were randomly assigned to the study groups according to an allocation sequence designated to generate a balanced ratio between the groups. Subjects in the intervention group were given treatment with oxygen-enriched air $\left(35 \% \mathrm{O}_{2}\right)$ through a nasal tube, $7 \mathrm{~h}$ per night for 1 month. Subjects in the control group were given treatment with room air $\left(21 \% \mathrm{O}_{2}\right)$ through a nasal tube, $7 \mathrm{~h}$ per night for 1 month. It is important to reiterate that the procedure of supplying $35 \% \mathrm{O}_{2}$ or $21 \% \mathrm{O}_{2}$ to study participants appeared identical in its entirety. Neither the research nurse nor the participants could recognize which $\mathrm{FiO}_{2}$ each participant received; namely, both the research nurse and the participants were blind to the treatment allocation.

Assessment tools. (1) The 21-item HRSD $39,70,74$ - This is a clinician rated scale aimed at assessing depression severity. It includes 21 items intended to assess: depressed mood; feelings of guilt; suicide; insomnia; work and activities; retardation; agitation; anxiety (psychological and somatic); somatic symptoms (gastrointestinal and general); genital symptoms; hypochondriasis; weight loss; insight; diurnal variation; derealization/depersonalization; paranoid symptoms; and obsessive/compulsive symptoms ${ }^{39,70,74}$. Of the 21 items, ten have scores ranging from 0 to 4 points, nine with scores ranging from 0 to 2 points, and two with scores ranging from 0 to 3 points. Thus, the general score may be between $0-64$. The widely accepted cut-off scores are: $<8$, normal; $8-13$, mild depression; 14-18, moderate depression; 19-22, severe depression; $>23$, very severe depression ${ }^{40,41,45}$. The inter-rater reliability of the 21 -item HRSD was found high (correlation coefficient $=0.81$ ) in a randomized, placebo-controlled, double-blind trial of patients with treatment-resistant depression ${ }^{41}$. (2) The CGI scale ${ }^{75}-$ This scale comprises two companion one-item measures evaluating the following: (i) Severity of psychopathology (on a scale of 1-7) and (ii) change from the commencement of treatment (on a scale of 1-7). CGI-severity is rated on the following scale: $1=$ normal, not at all ill; 2 =borderline mentally ill; $3=$ mildly ill; $4=$ moderately ill; $5=$ markedly ill; $6=$ severely ill; $7=$ among the most extremely ill patients. CGI-improvement (change): $1=$ very much improved since initiation of treatment; $2=$ much improved; $3=$ minimally improved; $4=$ no change from baseline; $5=$ minimally worse; $6=$ much worse; $7=$ very much worse since initiation of treatment ${ }^{75}$. (3) WHO$5-Q O L^{76}$ - This is a five-item instrument designed to measure overall quality of life. Each of the five items is rated on a 6 -point scale: $0=$ not present; $5=$ constantly present. The theoretical score ranges from 0 to 25 . Higher scores mean better well-being ${ }^{76}$. A score below 13 indicates poor well-being and is an indication for testing for depression. (4) SOC 13-items questionnaire ${ }^{77}$-The SOC theory is a theoretical model that explains successful coping with stressors ${ }^{78}$. According to the theory, the stronger the SOC, the more likely the person will be able to cope with life stressors. The questionnaire includes 13-items on a 7-point scale, with two anchoring responses: "never" and "very often". The range of the score is between 13 and 91; a high score represents a strong SOC ${ }^{77,79}$. The instrument has a Cronbach's alpha of 0.74-0.91 and $r=0.91^{79}$. (5) $S D S^{80}$-This instrument includes three self-rated items designed to measure the extent to which (i) work, (ii) social life/leisure activities, and, (iii) home life or family responsibilities, are impaired by panic, anxiety, phobic or depressive symptoms ${ }^{80}$. Each item is rated on a $0-10$ scale. The three items may be summed into a single dimensional measure of global functional impairment that ranges from 0 (unimpaired) to 30 (highly impaired). The tool has a Cronbach's alpha of $0.89^{81}$. Using these tools, assessments were performed at three time points: baseline, 2 weeks and 4 weeks after treatment initiation. All clinical ratings were performed in a family medicine clinic of Clalit Health Services under the direction of one of the authors (P.S.). The nurse who performed all assessments (Ye.Bl.) was blinded to the treatment conditions of each participant.

Adherence to treatment. Participants of the study were administered oxygen-enriched air or room air for $7 \mathrm{~h}$ per night for a month. The rate of adherence to treatment was assessed by measuring the amount of exposure time to treatment regimens/time using the oxygen generator by participants. The maximal possible amount of treatment hours for each participant during the study was $210 \mathrm{~h}(7 \mathrm{~h} \times 30$ days). There was no significant difference between the oxygen-treated group and the room-air-treated group in the number of hours using the oxygen generator (T-test; mean $\pm \mathrm{SD}, 120.1 \pm 29.62$ vs. $124.6 \pm 33.97, \mathrm{df}=49, \mathrm{t}=0.506,95 \% \mathrm{CI}-22.5$ to $13.4, \mathrm{P}=0.62$ ) nor in the proportion of participants with moderate or high rate of adherence (Chi-Square test; $\mathrm{P}=0.08$ ).

Statistical analyses. A multivariate regression analysis was performed using Stata 12.0 (Stata Corp, College Station, TX, USA), according to accepted methodology ${ }^{82}$. The Lagrange Multiplier Test $t^{82}$ examines the effect on the first order conditions for a maximum of the likelihood of imposing parametric hypothesis. There have been several reports illustrating and advocating the use of this method for multivariate analysis, particularly, multivariate regression. The key property of multivariate regression using the Lagrange Multiplier test is that several dependent variables are jointly regressed on the same independent variables. In the present study, the analysis determined the difference between the groups by comparing the mean and standard error of mean of the groups in terms of HRSD, CGI, SOC-13, WHO-5-QOL and SDS values. In our analysis of total HRSD score, 
the reported significance level for oxygen treatment is 0.007 , which approximately equals to $0.05 / 8$ (where eight is the number of the independent variables in the equation). A multivariate regression analysis was also preformed stratifying each subscale factor of the HRSD to the total change from baseline to week four. In this analysis, the reported significance level for each factor is 0.008 , which approximately equals to $0.05 / 6$ (where six is the number of the sub-scale factors of the HRSD). Calculation of the effect of oxygen treatment and contribution of each subscale factor of the HRSD to the total change from baseline to week four was done as follows: $\Delta$ value of subscale factor (baseline - week four) $/ \Delta$ total HRSD score (baseline - week four) $\times 100$. Differences in basic and clinical characteristics between the groups were tested using $T$-test (parametric variables) and chi-square test (non-parametric variables). Chi-square test was used and Yates correction was performed in cases with less than 10 points in a cell. Values of $\mathrm{P}<0.05$ were considered statistically significant.

Ethical considerations. Only participants who provided written informed consent to participate in the study were included. This study was approved by the institutional ethical review board (Helsinki Committee) of Clalit Health Services (approval \# 051/2013). The trial registration number at NIH.GOV was NCT02149563 (29/05/2014). The study was funded by the National Alliance for Research on Schizophrenia \& Depression Independent Investigator Award (to Yu.Be.).

\section{Data availability}

The data that support the findings of this study are available from the corresponding author upon reasonable request.

Received: 10 April 2021; Accepted: 31 August 2021

Published online: 23 September 2021

\section{References}

1. Malhi, G. S. \& Mann, J. J. Depression. Lancet 392, 2299-2312 (2018).

2. Park, L. T. \& Zarate, C. A. Depression in the primary care setting. N. Engl. J. Med. 380, 559-568 (2019).

3. Whiteford, H. A. et al. Global burden of disease attributable to mental and substance use disorders: Findings from the Global Burden of Disease Study 2010. Lancet 382, 1575-1586 (2013).

4. Kuehner, C. Why is depression more common among women than among men?. Lancet Psychiatry 4, 146-158 (2017).

5. Hirschfeld, R. M. A. The epidemiology of depression and the evolution of treatment. J. Clin. Psychiatry 73, 5-9 (2012).

6. Ferrari, A. J. et al. The epidemiological modelling of major depressive disorder: Application for the global burden of disease study 2010. PLoS One 8, e69637 (2013).

7. Cipriani, A. et al. Comparative efficacy and acceptability of 21 antidepressant drugs for the acute treatment of adults with major depressive disorder: A systematic review and network meta-analysis. Lancet 391, 1357-1366 (2018).

8. Li, J. M. et al. Cognitive behavioral therapy for treatment-resistant depression: A systematic review and meta-analysis. Psychiatry Res. 268, 243-250 (2018).

9. Lisanby, S. H. Electroconvulsive therapy for depression. N. Engl. J. Med. 357, 1939-1945 (2007).

10. Nakagawa, A. et al. Effectiveness of supplementary cognitive-behavioral therapy for pharmacotherapy-resistant depression: A randomized controlled trial. J. Clin. Psychiatry 78, 1126-1135 (2017).

11. McAllister-Williams, R. H. et al. Reconceptualising treatment-resistant depression as difficult-to-treat depression. Lancet Psychiatry 8, 14-15 (2021).

12. Gunduz-Bruce, H. et al. Trial of SAGE-217 in patients with major depressive disorder. N. Engl. J. Med. 381, 903-911 (2019).

13. Phillips, J. L. et al. Single, repeated, and maintenance ketamine infusions for treatment-resistant depression: A randomized controlled trial. Am. J. Psychiatry 176, 401-409 (2019).

14. Papakostas, G. I. et al. Efficacy of esketamine augmentation in major depressive disorder: A meta-analysis. J. Clin. Psychiatry 81, $19 \mathrm{r} 12889$ (2020)

15. Shao, L. et al. Mitochondrial involvement in psychiatric disorders. Ann. Med. 40, 281-295 (2008).

16. Ben-Shachar, D. \& Karry, R. Neuroanatomical pattern of mithochondrial complex I pathology varies between schizoprenia, bipolar disorder and major depression. PLoS One 3, e3676 (2008).

17. Kim, M. Y., Lee, J. W., Kang, H. C., Kim, E. \& Lee, D. C. Leukocyte mitochondrial DNA (mtDNA) content is associated with depression in old women. Arch. Gerontol. Geriatr. 53, e218-221 (2011).

18. Holper, L., Ben-Shachar, D. \& Mann, J. Multivariate meta-analyses of mitochondrial complex I and IV in major depressive disorder, bipolar disorder, schizophrenia, Alzheimer disease, and Parkinson disease. Neuropsychopharmacology 44, 837-849 (2019).

19. Menzel, M. et al. Increased inspired oxygen concentration as a factor in improved brain tissue oxygenation and tissue lactate levels after severe human head injury. J. Neurosurg. 91, 1-10 (1999).

20. Brugniaux, J. V. et al. Highs and lows of hyperoxia: Physiological, performance, and clinical aspects. Am. J. Physiol. Regul. Integr. Comp. Physiol. 315, R1-R27 (2018).

21. Chen, S. et al. Homocysteine exaggerates microglia activation and neuroinflammation through microglia localized STAT3 overactivation following ischemic stroke. J. Neuroinflamm. 14, 1-12 (2017).

22. Terraneo, L. \& Samaja, M. Comparative response of brain to chronic hypoxia and hyperoxia. Int. J. Mol. Sci. 18, 1914 (2017).

23. Doppenberg, E. M. R. et al. Increased free radical production due to subdural hematoma in the rat: Effect of increased inspired oxygen fraction. J. Neurotrauma 15, 337-347 (1998).

24. Duong, T. Q., Iadecola, C. \& Kim, S.-G. Effect of hyperoxia, hypercapnia, and hypoxia on cerebral interstitial oxygen tension and cerebral blood flow. Magn. Reson. Med. 45, 61-70 (2001).

25. Meier, M. H. et al. Retinal Imaging shows microvascular abnormality in schizophrenia-News \& Events | The Dunedin StudyDunedin Multidisciplinary Health \& Development Research Unit. Am. J. Psychiatry 170, 1451-1459 (2013).

26. Zhang, J., Zhang, H., Chen, J., Fan, M. \& Gong, Q. Structural modulation of brain development by oxygen: Evidence on adolescents migrating from high altitude to sea level environment. PLoS One 8, e67803 (2013).

27. Shi, S. et al. Normobaric hyperoxia reduces blood occludin fragments in rats and patients with acute ischemic stroke. Stroke 48 , 2848-2854 (2017).

28. Bloch, Y. et al. Normobaric hyperoxia treatment of schizophrenia. J. Clin. Psychopharmacol. 32, 525-530 (2012).

29. Gui, Y., Li, H., Zhao, M., Yang, Q. \& Kuang, X. Effect of intermittent normobaric hyperoxia for treatment of neuropathic pain in Chinese patients with spinal cord injury. Spinal Cord 53, 238-242 (2014).

30. Roffe, C. et al. Effect of routine low-dose oxygen supplementation on death and disability in adults with acute stroke: The stroke oxygen study randomized clinical trial. J. Am. Med. Assoc. 318, 1125-1135 (2017). 
31. McMonnies, C. W. Hyperbaric oxygen therapy and the possibility of ocular complications or contraindications. Clin. Exp. Optom. 98, 122-125 (2015).

32. Plafki, C., Peters, P., Almeling, M., Welslau, W. \& Busch, R. Complications and side effects of hyperbaric oxygen therapy. Aviat. Space Environ. Med. 71, 119-124 (2000).

33. Butler, F. K., Hagan, C. \& Murphy-Lavoie, H. Hyperbaric oxygen therapy and the eye. Undersea Hyperb. Med. J. Undersea Hyperb. Med. Soc. 35, 333-387 (2008).

34. Heyboer, M., Sharma, D., Santiago, W. \& McCulloch, N. Hyperbaric oxygen therapy: Side effects defined and quantified. Adv. Wound Care 6, 210-224 (2017).

35. Michalski, D., Härtig, W., Schneider, D. \& Hobohm, C. Use of normobaric and hyperbaric oxygen in acute focal cerebral ischemiaA preclinical and clinical review. Acta Neurol. Scand. 123, 85-97 (2011).

36. Bennett, M. \& Heard, R. Hyperbaric oxygen therapy for multiple sclerosis. CNS Neurosci. Ther. 16, 115-124 (2010).

37. Efrati, S. et al. Hyperbaric oxygen induces late neuroplasticity in post stroke patients-Randomized, prospective trial. PLoS One 8, e53716 (2013).

38. Boussi-Gross, R. et al. Hyperbaric oxygen therapy can improve post concussion syndrome years after mild traumatic brain injuryRandomized prospective trial. PLoS One 8, e79995 (2013).

39. Kearns, N. P. et al. A comparison of depression rating scales. Br. J. Psychiatry 141, 45-49 (1982).

40. Frank, E. et al. Conceptualization and rationale for consensus definitions of terms in major depressive disorder. Remission, recovery, relapse, and recurrence. Arch. Gen. Psychiatry 48, 851-855 (1991).

41. Zarate, C. et al. A randomized trial of an N-methyl-D-aspartate antagonist in treatment-resistant major depression. Arch. Gen. Psychiatry 63, 856-864 (2006).

42. Rockswold, S. B. et al. A prospective, randomized clinical trial to compare the effect of hyperbaric to normobaric hyperoxia on cerebral metabolism, intracranial pressure, and oxygen toxicity in severe traumatic brain injury: Clinical article. J. Neurosurg. 112, 1080-1094 (2010).

43. Loscalzo, J. Is oxygen therapy beneficial in acute myocardial infarction? Simple question, complicated mechanism, simple answer. N. Engl. J. Med. 377, 1286-1287 (2017).

44. Stub, D. et al. Air versus oxygen in ST-segment-elevation myocardial infarction. Circulation 131, 2143-2150 (2015).

45. Chu, D. K. et al. Mortality and morbidity in acutely ill adults treated with liberal versus conservative oxygen therapy (IOTA): A systematic review and meta-analysis. Lancet 391, 1693-1705 (2018).

46. Hofmann, R. et al. Oxygen therapy in suspected acute myocardial infarction. N. Engl. J. Med. 377, 1240-1249 (2017).

47. Ali, K. et al. The stroke oxygen pilot study: A randomized controlled trial of the effects of routine oxygen supplementation early after acute stroke-effect on key outcomes at six months. PLoS One 8, e59274 (2013).

48. Vidal-Jorge, M. et al. Does normobaric hyperoxia cause oxidative stress in the injured brain? A microdialysis study using 8-isoprostaglandin F2 $\alpha$ as a biomarker. J. Neurotrauma 34, 2731-2742 (2017).

49. Almutairi, H. J., Mussa, C. C., Lambert, C. T. M., Vines, D. L. \& Strickland, S. L. Perspectives from COPD subjects on portable long-term oxygen therapy devices. Respir. Care 63, 1321-1330 (2018).

50. Yáñez, A. M. et al. Oxygenation with a single portable pulse-dose oxygen-conserving device and combined stationary and portable oxygen delivery devices in subjects with COPD. Respir. Care 60, 382-387 (2015).

51. Yan, D., Shan, J., Ze, Y., Xiao-Yan, Z. \& Xiao-Hua, H. The effects of combined hyperbaric oxygen therapy on patients with poststroke depression. J. Phys. Ther. Sci. 27, 1295-1297 (2015).

52. Liang, X., Hao, Y., Duan, X., Han, X. \& Cai, X. Hyperbaric oxygen therapy for post-stroke depression: A systematic review and meta-analysis. Clin. Neurol. Neurosurg. 195, 105910 (2020).

53. Chen, X. et al. Interleukin-10 mediates the neuroprotection of hyperbaric oxygen therapy against traumatic brain injury in mice. Neuroscience 266, 235-243 (2014).

54. Chen, L. et al. Repetitive hyperbaric oxygen therapy provides better effects on brain inflammation and oxidative damage in rats with focal cerebral ischemia. J. Formos. Med. Assoc. Taiwan yi zhi 113, 620-628 (2014).

55. Need Fresh Air? Japan Sells Oxygen-to-Go-ABC News. https://abcnews.go.com/International/story?id=1999240\&page=1. Accessed 30 Mar 2020.

56. Levine, J. et al. Double-blind, controlled trial of inositol treatment of depression. Am. J. Psychiatry 152, 792-794 (1995).

57. Nemets, B., Stahl, Z. \& Belmaker, R. H. Addition of omega-3 fatty acid to maintenance medication treatment for recurrent unipolar depressive disorder. Am. J. Psychiatry 159, 477-479 (2002).

58. Liao, Y. et al. Efficacy of omega-3 PUFAs in depression: A meta-analysis. Transl. Psychiatry 9, 190 (2019).

59. Deane, K. et al. Omega-3 and polyunsaturated fat for prevention of depression and anxiety symptoms: Systematic review and meta-analysis of randomised trials. Br. J. Psychiatry J. Ment. Sci. 218, 135-142 (2021).

60. Sugarman, M. A., Loree, A. M., Baltes, B. B., Grekin, E. R. \& Kirsch, I. The Efficacy of paroxetine and placebo in treating anxiety and depression: A meta-analysis of change on the Hamilton rating scales. PLoS One 9, e106337 (2014).

61. Jakobsen, J. et al. Selective serotonin reuptake inhibitors versus placebo in patients with major depressive disorder. A systematic review with meta-analysis and Trial Sequential Analysis. BMC Psychiatry 17, 58 (2017).

62. Li, F., Nasir, M., Olten, B. \& Bloch, M. H. Meta-analysis of placebo response in adult antidepressant trials. CNS Drugs 33, 971-980 (2019).

63. Walsh, T. B., Seidman, S. N., Sysko, R. \& Gould, M. Placebo response in studies of major depression: Variable, substantial, and growing. J. Am. Med. Assoc. 287, 1840-1847 (2002).

64. Schalkwijk, S., Undurraga, J., Tondo, L. \& Baldessarini, R. Declining efficacy in controlled trials of antidepressants: Effects of placebo dropout. Int. J. Neuropsychopharmacol. 17, 1343-1352 (2014).

65. Nagele, P. et al. Nitrous oxide for treatment-resistant major depression: A proof-of-concept trial. Biol. Psychiatry. 78, 10-18 (2015).

66. Nettis, M. A. et al. Augmentation therapy with minocycline in treatment-resistant depression patients with low-grade peripheral inflammation: Results from a double-blind randomised clinical trial. Neuropsychopharmacology 46, 939-948 (2021).

67. Carhart-Harris, R. et al. Trial of psilocybin versus escitalopram for depression. N. Engl. J. Med. 384, 1402-1411. https://doi.org/ 10.1056/NEJMoa2032994 (2021).

68. First, M., Spitzer, R., Gibbon, M. \& Willians, J. Structured clinical interview for DSM-IV axis I disorders. In Clinician Version (SCID-CV) (American Psychiatric Press, 1996).

69. American Psychiatric Association. Diagnostic and Statistical Manual of Mental Disorders (American Psychiatric Association, 2013).

70. Kyle, P. R. et al. The validity of the different versions of the Hamilton depression scale in separating remission rates of placebo and antidepressants in clinical trials of major depression. J. Clin. Psychopharmacol. 36, 453-456 (2016).

71. Abbasi, S., Hosseini, F., Modabbernia, A., Ashrafi, M. \& Akhondzadeh, S. Effect of celecoxib add-on treatment on symptoms and serum IL-6 concentrations in patients with major depressive disorder: Randomized double-blind placebo-controlled study. J. Affect. Disord. 141, 308-314 (2012).

72. Müller, N. et al. The cyclooxygenase-2 inhibitor celecoxib has therapeutic effects in major depression: Results of a double-blind, randomized, placebo controlled, add-on pilot study to reboxetine. Mol. Psychiatry 11, 680-684 (2006).

73. Hardavella, G., Karampinis, I., Frille, A., Sreter, K. \& Rousalova, I. Oxygen devices and delivery systems. Breathe 15, e108-e116 (2019).

74. Hamilton, M. A rating scale for depression. J. Neurol. Neurosurg. Psychiatry 23, 56-62 (1960). 
75. Busner, J. \& Targum, S. D. The clinical global impressions scale: Applying a research tool in clinical practice. Psychiatry (Edgmont (Pa. : Township)) 4, 28-37 (2007).

76. Primack, B. A. The WHO-5 Wellbeing Index performed the best in screening for depression in primary care. ACP J. Club 139, 48-48 (2003).

77. Antonovsky, A. The structure and properties of the sense of coherence scale. Soc. Sci. Med. 36, 725-733 (1993).

78. Antonovsky, A. Unravelling the mystery of health: How people manage stress and stay well. (1978).

79. Pallant, J. F. \& Lae, L. Sense of coherence, well-being, coping and personality factors: Further evaluation of the sense of coherence scale. Personal. Individ. Differ. 33, 39-48 (2002).

80. Sheehan, K. H. \& Sheehan, D. V. Assessing treatment effects in clinical trials with the Discan metric of the Sheehan Disability Scale. Int. Clin. Psychopharmacol. 23, 70-83 (2008).

81. Sheehan, D. V. et al. The validity of the Mini International Neuropsychiatric Interview (MINI) according to the SCID-P and its reliability. Eur. Psychiatry 12, 232-241 (1997).

82. Breusch, T. S. \& Pagan, A. R. The Lagrange Multiplier Test and its applications to model specification in econometrics. Rev. Econ. Stud. 47, 253 (1980).

\title{
Acknowledgements
}

The authors thank Dr. Julia Appelbaum (M.D.) for her help in determining and assuring a high rater reliability score of the HRSD assessment by Ye.B.

\section{Author contributions}

Ye.B. participated in the design of the study and played the major role in the process of patients' recruitment; performed all clinical evaluations of study participants; took part in the analysis of the data and in writing the manuscript. R.H.B. participated in the design of the study, took part in the analysis of the data and in writing the manuscript. P.S. participated in the design of the study, in obtaining the ethical approvals of study procedures, and contributed to patients' recruitment. P.R. (of blessed memory) participated in the design of the study and contributed to patients' recruitment. A.B. participated in the design of the study and performed most of the statistical analysis of the results. Yu.B. participated in the design of the study and in coordination of all study procedures; conducted the initial psychiatric evaluations of patients recruited to the study, took part in analysis of the data and statistical analysis and helped writing the manuscript. A.N.A. participated in the design of the study and in coordination of all study procedures and took part in analysis of the data and in writing the manuscript. All authors (except P.R.) read and approved the submission of the manuscript.

\section{Funding}

The study was funded by a National Alliance for Research on Schizophrenia \& Depression Independent Investigator Award (Award number: 8942801). NARSAD had no further role in study design; in the collection, analysis and interpretation of data; in the writing of the report; and in the decision to submit the paper for publication.

\section{Competing interests}

The authors declare no competing interests.

\section{Additional information}

Correspondence and requests for materials should be addressed to A.N.A.

Reprints and permissions information is available at www.nature.com/reprints.

Publisher's note Springer Nature remains neutral with regard to jurisdictional claims in published maps and institutional affiliations.

\begin{abstract}
Open Access This article is licensed under a Creative Commons Attribution 4.0 International License, which permits use, sharing, adaptation, distribution and reproduction in any medium or format, as long as you give appropriate credit to the original author(s) and the source, provide a link to the Creative Commons licence, and indicate if changes were made. The images or other third party material in this article are included in the article's Creative Commons licence, unless indicated otherwise in a credit line to the material. If material is not included in the article's Creative Commons licence and your intended use is not permitted by statutory regulation or exceeds the permitted use, you will need to obtain permission directly from the copyright holder. To view a copy of this licence, visit http://creativecommons.org/licenses/by/4.0/.
\end{abstract}

(C) The Author(s) 2021 